\title{
Effect of Implementing Intra-Aortic Balloon Pump Teaching Program on Critical Care Nurse's knowledge and Practice
}

\author{
Asmaa AlyMahgoub1*, Aml Ismael AbdEl Hafez1, \\ 1-Lecturer of Critical care \& emergency Nursing, Faculty of Nursing, Assuit University, Egypt.
}

\begin{abstract}
Background: Intra-aortic balloon pump (IABP) counterpulsation is the most widely used therapy for support of a compromised left ventricle. Therefore, critical care nurses not only have to know how to monitor and operate the IABP, but also to provide interventions for preventing possible complications.

Objective of the study: To evaluate the effect of implementing intra-aortic balloon pump teaching program on critical care nurse's knowledge and practice.

Research design: Pre/post research design was used to conduct the study. Convenience samples of 40 nurses were included in the current study.

Setting: This study was carried out at the post-operative cardiothoracic surgery and coronary care units at Assuit Main University hospital.

Tools of data collection: Two tools were used for data collection. Tool I (pre/post IABP knowledge questionnaire tool). Tool II (pre/post IABP nurse's practice observational checklists tool.).The current study was carried out on the assessment of the nurse's level of knowledge and practice using tool I and tool II. Followed by implementation of teaching program where all study sample was exposed to ten sessions and reassessment carried out.

Results: The study revealed that the majority of nurses had poor knowledge and practice related to IABP before teaching program which has been improved after Also, a positive correlation was found between knowledge and practice scores of the study subjects. In conclusion, empowerment of critical care nurse's knowledge and practice would have a positive impact upon their knowledge and performance. The study recommended that continuous In service training programs for the purpose of updating the knowledge and practice about IABP for critical care nurses
\end{abstract}

Keywords: knowledge, practice, teaching program, IABP, critical care nurse

\section{Introduction}

Intra-aortic balloon pump (IABP) is the most widely used temporary mechanical circulatory assist device for supporting failing circulation. Today; more than 160000 patients worldwide receive this therapy annually. The primary purpose of IABP is the support of the failing heart by simultaneously increasing myocardial oxygen supply and decreasing myocardial oxygen demand .IABP catheter consists of a single ,sausage -shaped polyurethane balloon that is wrapped around the distal end of avascular catheter and positioned in the descending thoracic aorta just distal to the take off the left subclavian artery and is attached to an external drive console which inflates and deflates the IAB in synchrony with cardiac contraction .( Urden ,Stancy ,Lough,2010 )

The goal therapy is to improve perfusion pressure to the coronary and systemic circulation. The IAB is inflated at the onset of diastole when blood ceases to eject from the heart. Balloon deflation is timed to occur immediately before to the onset of systole. Aortic pressure is reduced just before systole by removing volume from the aorta to reduce afterload for the next left ventricular ejection. With reduced arterial resistance, the heart can eject a greater stroke volume at a lower work level, effectively reducing myocardial oxygen demand, and reduce preload and improve myocardial efficiency.(woodruff,2016) IABP indicates for therapy of refractory unstable angina, impending infarction ,acute myocardial infarction ,support during percutaneous coronary intervention ,complications post myocardial infarction as papillary muscle rupture and acute mitral regurgitation ,myocardial contusion, ischemia related intractable ventricular arrhythmias and bridge to cardiac transplantation .(Hanlon-Pena and Quaal,2011)

Nursing care for patient connected with IABP involves care of the pump as well as assessing patient from a cardiovascular and hemodynamic perspective. The management of the pumping console and its timing functions performed by the critical care nurse caring for the patient. There are multiple factors that may affect the efficacy of the IABP, including positioning of the balloon within the aorta the balloon displacement volume ,inflation/deflation timing, signal quality , the patient cardiac function and hemodynamic variables ,which includes circulating blood volume, blood pressure and vascular resistance .The critical care nurse need to be aware of these factors in order to adequately assess for and ensure optimal IABP performance.( Ward , 
Courtney and Mary ,2009) Prior to insertion of the IABP a baseline assessment is performed incorporating upper and lower limbs perfusion. Upper limb assessment is essential so that balloon migration obstructing blood flow down the left subclavian artery can be detected promptly. (Tscheschlog,Jauch,2015).This assessment involves documentation of palpation of the relevant pulses, assessing capillary refill, temperature and color of the limbs. A set of baseline vital signs is recorded heart rate, blood pressure, respiratory rate, oxygen saturations and temperature, which are used to assess improvement or deterioration in the patient's condition. (Morton and fontane2012)

Following insertion, nursing care involves cardiovascular and hemodynamic assessment, fluid balance, positioning and pressure area care, observation of the balloon catheter and line, the catheter insertion site, limb perfusion, neurological status and providing psychological support for patient and family. To establish IAB support carful secure cables connected with console. Cardiovascular assessment involves heart rate and rhythm, augmented, mean arterial pressure, temperature, respiratory rate and oxygen saturations. The aim is that the mean arterial pressure is maintained between $60-70 \mathrm{mmHg}$ which indicates adequate peripheral perfusion. This is confirmed by the patient being warm to touch, good capillary refill, no evidence of cerebral hypoxia and urinary output equal $0.5 \mathrm{ml} / \mathrm{kg} / \mathrm{hr}$. Cardiovascular assessment is performed hourly or more frequently if hemodynamic status deteriorates.( Urden ,Stancy,Lough ,2010)

Critical care nurse have a vital role after catheter insertion involves checking the insertion site every hour for bleeding or hematoma formation and documenting findings. In addition the full blood count and anticoagulation screen is observed for a decrease in hemoglobin and platelet count or evidence that the patient is receiving too high dose of anticoagulant. The insertion site dressing should be transparent which enables visual inspection of the site. Change of dressing is as per clinical need and hospital guidelines, aseptic technique must be employed to minimize the risk of infection. Frequency of monitoring depends on patient's clinical condition and as acuity determines. Indications of bleeding may manifest as oozing, bruising or hematoma formation at the insertion site or by swelling in the thigh area. (Parissisetal 2010) The pump should be checked hourly for correct settings such as timing, balloon inflating to its maximum capacity and that the trigger is at the correct setting. As with any invasive hemodynamic monitoring system the pressure bag should be inflated and maintained at $300 \mathrm{mmHg}$, thus ensuring optimal flush system, which is required for line patency. The level of the transducer is at the phlebostatic axis that is confirmed using the spirit level and is changed as per patient position. Patient position is an important consideration if the IABP is to be effective. The patient should be no higher than $30^{\circ}$, which ensures patency of the balloon, continuous flow to the balloon, and reduces the risk of catheter kinking and obstructing the passage of helium into and out of the catheter.(Huang, H.and Hsu, 2012)

Once the patient's condition has stabilized the IABP is considered for removal. This is preceded by a process of weaning the pump from $1: 1$ to $1: 2$ and finally 1:3.Observing the patient by critical care nurse for ischemic chest pain or development of heart failure symptoms such as breathlessness, hypotension and tachycardia. Once the patient is stable the IABP can be removed. Post removal the patient is kept on bed rest with the leg kept straight as per local guidelines. Nurses play a crucial role in caring for patients receiving IABP therapy. Nurses who care for patients managed with IABP require knowledge of the mechanisms and actions of this therapeutic device. As well as addressing IABP physiology, benefits, potential complications and safety considerations .Finally the current study aimed to evaluate effect of implementing intra-aortic balloon pump teaching program on critical care nurse's knowledge and practice. (Ward , Courtney and Mary ,2009)

\section{Objective of the study}

The aim aimed to evaluate the effect of implementing intra-aortic balloon pump teaching program on critical care nurse's knowledge and practice

\section{Hypothesis}

-There will be significant difference between posttest knowledge scores to the pretest knowledge scores following implementation of teaching program.

-There will be significant difference between post test practice scores to the pretest practice scores following implementation of teaching program.

-A positive relation will exist between knowledge and practice score obtained by critical care nurses receiving teaching program.

\section{Patients and method}

Research design: A quasi experimental research design with one group pre-test post-test approach was used to evaluate the effectiveness of structured teaching program for the present study. Thus only one group is observed twice (before and after introducing the independent variable).

\section{Study variables:}

-The independent variable was the teaching program and the dependent variable was critical care nurses' knowledge and practice. 
Setting: The study was conducted in post-operative cardiothoracic surgery and coronary care units at Assuit Main University hospital

Subjects: A purposive sample of approximately fourty critical care nurses who are involved in providing direct patient care in the previously mentioned ICUs and willing to participate in this study.

\section{Study tools: Two tools were used in this study:}

- Tool I(pre/post IABP knowledge questionnaire tool): This tool consisted of Structured multiple choice questions. This tool was developed by researcher after reviewing literatures ${ }^{(1-6)}$ to assess the level of knowledge for critical care nurses about IABP care. It was translated into Arabic language. It was consist of twenty questions covering the theoretical aspect which was focus on; anatomy and physiology related IABP, Principles and hemodynamic effects, Indications, contraindications and complications of IABP. In addition to Scio-demographic data of study sample which includes: age, sex, educational level, marital status, years of experience, and previous training program.

Scoring system for nurses' knowledge: All items had four alternative answers. A score value of 1 was awarded to each correct answer and zero was allotted for wrong answer. The total score of nurses' knowledge was calculated and classified as follows: $75 \%$ and more was considered good, 74-60\% was considered fair, and less than $60 \%$ was considered poor.

- Tool II: pre/post IABP nurse's practice observational checklists tool. It was developed by the researcher after reviewing the related literature ${ }^{.(2,6-10)}$ this tool was used to assess the baseline nurse's practice about IABP .It was consist of fourty steps covering the practical aspects which focus on nursing preparation and initiation of IABP Therapy (steps from 1-11),immediately nursing care(steps from 12-14), care of central lumen(steps from 15-20), general assessment guidelines (steps from 21-26), and nursing consideration during weaning and IABP removal (steps from 27-40).

Scoring system for nurse's practice: The total score for all steps were 40 and every step was evaluated as follows; correctly done was scored (2), in-correctly done was scored (1) and not done was scored (0).

Construction of the teaching program: The teaching program was developed by the researcher based on the previous assessment of nurse's knowledge and practice, available resources and review of relevant literature. $(3,6,13)$

Objectives of the program :By the completion of this teaching program, critical care nurses will be able to:-

1. List indications for intra-aortic balloon pumping in intensive care unit.

2. Discuss the insertion procedure and catheter position

3. Identify correct timing of balloon inflation and deflation

4. Describe the physiological effects of IABP

5. Discuss nursing management of IABP about weaning, complications and troubleshooting machine problems

6. Communicate effectively with team work

\section{Methods}

The study was conducted on three phases (preparatory phase, implementation phase and evaluation phase).

Preparatory phase

- Permission to conduct the study was obtained from the hospital responsible authorities after explanation of the aim of the study.

- An approval was obtained from the local ethical committee and the study was followed the common ethical principles in clinical research.

- Tools and booklet used in this study were developed in Arabic by the researcher based on reviewing the relevant literature. ${ }^{(1-6,16,18)}$

- The reliability was test for tool I and tool II by using Cronbach'scoaefficient alpha ( $\mathrm{r}=0.867,0.94$ respectively) which is acceptable.

- A pilot study was conducted on four nurses to test the feasibility and applicability of the tool and the necessary modification was done.

- Permission for voluntary participation was obtained from nurses after the purpose and nature of the study was explained.

- Content validity of both tools and teaching program booklet done by 5 experts in the related fields and the necessary modification was done accordingly.

- The anonymity and confidentiality of response, voluntary participation and right to refuse to participate in the study was emphasized to the subject.

\section{Implementation phase:-}

The researcher filled out the socio-demographic and medical data sheet, Initial assessment of the baseline nurse's knowledge was done using tool I.The practical content was checked tool II for the study group. 


\section{For theoretical content:}

The teaching program has been implemented for nurses in terms of sessions, with a total of ten sessions. Number of nurses in each session ranged from 3-5nurses. The duration of each session was an two hours, including 10 minutes for discussion and feedback. The theoretical contents which focus on; anatomy and physiology related IABP, Principles and hemodynamic effects, indications and contraindications and complications of IABP.Each session usually started by a summary of what has been taught during this session and the objectives of the topics.Feedback and reinforcement of teaching was performed according to the nurses needs to ensure their understanding.

\section{For practical content:}

The researcher conducting demonstration using teaching materials (photos, video and application on the patient).This was done on a small sessions ranged from 3-5 nurses with a total of ten sessions. The researcher observes the nurse practice using observational checklist tool before and post program implementation. The researcher completes the checklist while the nurse demonstrates technique on patient. The duration of each session was a two hours, including 10 minutes for discussion and feedback. It included conventional slide presentation about caring patient with IABP and teaching program. The duration of each session was an two hours, including 10 minutes for discussion and feedback. It included conventional slide presentation about caring patient with IABP and teaching program.

Most nurses were able to ambulate and can master this skill easily .Then the immediately post practical test (tool II) was checked by the researcher for patient connected by IABP.

Theoretical and practical content were repeated according to the ability of understanding.

Then the researcher provided each nurse with the designed illustrated booklet.

\section{Evaluation phase:-}

Evaluation of program was carried out post knowledge and practice test to all nurses by using pre-test study tools to evaluate the effect of implementing intra-aortic balloon pump teaching program on critical care nurse's knowledge and practice

\section{Statistical analysis:}

- The data entry and data analysis were done using (SPSS Ver.19.).

- Descriptive statistics (number, percentage, mean and standard deviation) were done.

- Chi-square test was done to compare qualitative variables between before and after group .

- Independent samples t-test was done to compare quantitative variables between before and after group, and Pearson correlation between quantitative variables.

- $\quad \mathrm{P}$-value considered statistically significant when $\mathrm{p}<0.05$.

\section{Results}

Table (1) Shows the Scio-demographic data of studied nurses. It was found that $77.5 \%$ of them were in the age group less than 25 years, $100 \%$ were female. Concerning their educational level, $60 \%$ of the nurses held technical institute of nursing .Moreover, $80 \%$ nurses had work experience less than 5 years and $20 \%$ of them had more than 5 years' experience. In relation to their previous training on IABP, the table reveals that, $100 \%$ of them were not receiving any previous training workshop.

Table (1): The Scio-demographic data of studied nurses:

\begin{tabular}{|l|l|l|}
\hline Scio-demographic data & No. $(\mathbf{n}=\mathbf{4 0})$ & \% \\
\hline Age: & \multicolumn{2}{|l|}{} \\
\hline$<25$ years & 31 & 77.5 \\
\hline$\geq 25$ years & 9 & 22.5 \\
\hline Mean \pm SD (Range) & \multicolumn{2}{|l|}{$18.40 \pm 4.19(22.0-35.0)$} \\
\hline Level of education: & \multicolumn{2}{|l|}{} \\
\hline 3 Years Nursing Diploma & 16 & 40 \\
\hline Technical Institute of Nursing & 24 & 60 \\
\hline Experience: & \multicolumn{2}{|l}{} \\
\hline$<5$ years & 32 & 80 \\
\hline$\geq 5$ years & 8 & 20 \\
\hline Mean \pm SD (Range) & $2.94 \pm 4.96(1.0-19.0)$ & \\
\hline Training workshp: & \multicolumn{2}{|l}{} \\
\hline Yes & 0 & 0 \\
\hline No & 40 & 100 \\
\hline
\end{tabular}


Table (2): Percentage distribution of nurse's knowledge regarding anatomy and physiology of the heart before and after teaching program. This table reveals that the answers of $(37.5 \%$ and $45 \%)$ of the nurse's regarding structure of the heart were correct before and after teaching program respectively. As regarding function of the heart, site and function of coronary arteries and cardiac cycle there were statistical significant differences before and after teaching program $\mathrm{p}$ value $(0.002,0.001 \& 0.025)$ respectively.

\begin{tabular}{|l|l|l|l|l|l|}
\hline \multirow{2}{*}{$\begin{array}{l}\text { The answer for knowledge about anatomy and } \\
\text { physiology of the heart }\end{array}$} & \multicolumn{2}{|l|}{ Before $(\mathbf{n = 4 0})$} & \multicolumn{2}{l|}{$\begin{array}{l}\text { After } \mathbf{4}(\mathbf{n}= \\
\text { 40) }\end{array}$} & \multirow{2}{*}{ P-value } \\
\cline { 2 - 5 } & No. & $\mathbf{\%}$ & $\mathbf{N o .}$ & $\mathbf{\%}$ & \\
\hline Q1-Structure of the heart & 15 & 37.5 & 18 & 45.0 & 0.496 \\
\hline Q2- Function of the heart & 11 & 27.5 & 25 & 62.5 & $0.002^{* *}$ \\
\hline Q3-Site and function of coronary arteries & 3 & 7.5 & 15 & 37.5 & $0.001^{* *}$ \\
\hline Q4-Cardiac cycle & 13 & 32.5 & 23 & 57.5 & $0.025^{*}$ \\
\hline
\end{tabular}

* Statistical significant difference $(\mathrm{P}<0.05)$

Table (3): illustrates Percentage distribution of nurses' knowledge regarding principles of IABP before and after teaching program. This table shows that highly Statistical significant difference before and after teaching program regarding definition of IABP, mechanism of counterpulsation \& positioning $(0.001,0.000 \& 0.005)$ respectively . Moreover, also present $(27.5 \%$ and $40.0 \%)$ of nurses' knowledge regarding efficacy of IABP were correct before and after teaching program.

\begin{tabular}{|l|l|l|l|l|l|}
\hline The answer for principle of IABP & \multicolumn{2}{l|}{$\begin{array}{l}\text { Before } \\
(\mathrm{n}=40)\end{array}$} & \multicolumn{2}{l|}{$\begin{array}{l}\text { After } \\
(\mathrm{n}=40)\end{array}$} & \multirow{2}{*}{ P-value } \\
\cline { 2 - 6 } & No. & $\%$ & No. & $\%$ & \\
\hline Q1-Definition of IABP & 17 & 42.5 & 31 & 77.5 & $0.001^{* *}$ \\
\hline Q2-Mechanism of IABP counterpulsation & 8 & 20.0 & 26 & 65.0 & $0.000^{* *}$ \\
\hline Q3- Positioning of the IAB Catheter & 20 & 50.0 & 32 & 80.0 & $0.005^{* *}$ \\
\hline Q4- Effect of IABP inflation & 8 & 20.0 & 30 & 75.0 & $0.000^{* *}$ \\
\hline Q5- When should the IABP be inflated & 16 & 40.0 & 30 & 75.0 & $0.002^{* *}$ \\
\hline Q6- Effect of IABP deflation & 9 & 22.5 & 31 & 77.5 & $0.000^{* *}$ \\
\hline Q7- When should the IABP be deflated & 11 & 27.5 & 28 & 70.0 & $0.000^{* *}$ \\
\hline Q8- Benefits of IABP therapy & 17 & 42.5 & 26 & 65.0 & $0.044^{*}$ \\
\hline $\begin{array}{l}\text { Q9-Which statement best describes the } \\
\text { physiologic effects of IABP deflation? }\end{array}$ & 8 & 20.0 & 27 & 67.5 & $0.000^{* *}$ \\
\hline $\begin{array}{l}\text { Q10-Hemodynamic effects of IABP } \\
\text { Counterpulsation }\end{array}$ & 16 & 40.0 & 30 & 75.0 & $0.002^{* *}$ \\
\hline Q11-Timing of Coronary artery perfusion & 5 & 12.5 & 27 & 67.5 & $0.000^{* *}$ \\
\hline Q12-Efficacy of IABP & 11 & 27.5 & 16 & 40.0 & 0.237 \\
\hline
\end{tabular}

* Statistical significant difference $(\mathrm{P}<0.05)$

Table (4): Percentage distribution of nurse's knowledge regarding indication and complications before and after teaching program. This table reveals that the answers (20\%and 52.5\%) of nurses' regarding indications of IABP were correct before and after teaching program. Moreover (20\% and 52.5\%)of nurses' answers regarding complications of IABP \&signs of weaning failure were correct before and after teaching program, while the answers of them $(52.5 \% \& 75 \%)$ were correct after teaching program respectively. There were statistical significant differences before and after teaching program $p$ value $(0.002)$.

\begin{tabular}{|l|l|l|l|l|l|}
\hline The answer for knowledge about indications & \multicolumn{2}{l|}{ Before $(\mathrm{n}=40)$} & \multicolumn{2}{l|}{ After $(\mathrm{n}=40)$} & \multirow{2}{*}{ P-value } \\
\cline { 2 - 5 } and complications & No. & $\%$ & No. & $\%$ & \\
\hline Q1-Indications of IABP & 8 & 20.0 & 21 & 52.5 & $0.002^{* *}$ \\
\hline Q2-Contraindications of IABP & 17 & 42.5 & 25 & 62.5 & 0.073 \\
\hline Q3-Complications conferred by the IABP. & 8 & 20.0 & 21 & 52.5 & $0.002^{* *}$ \\
\hline Q4- Signs of weaning failure & 16 & 40.0 & 30 & 75.0 & $0.002^{* *}$ \\
\hline
\end{tabular}

* Statistical significant difference $(\mathrm{P}<0.05)$

Table (5): Percentage distribution of the nurse's According to Practice checklist for patient connected with IABP. This table shows that the majority of nurses didn't demonstrate the appropriate steps before teaching $(35.0 \%, 25.0 \%, 27.5 \%, 37.5 \%$ and $27.5 \%)$ respectively. While the majority of nurse's demonstrate correctly after 
teaching program $(77.5 \%, 80 \%, 77.5 \%, 67.5 \% \& 55 \%)$ respectively. There were statistical significant differences before and after teaching program.

\begin{tabular}{|c|c|c|c|c|c|}
\hline \multirow{2}{*}{$\begin{array}{l}\text { Practice checklist for patient connected } \\
\text { with IABP }\end{array}$} & \multicolumn{2}{|c|}{$\begin{array}{l}\text { Before }(n= \\
\text { 40) }\end{array}$} & \multicolumn{2}{|c|}{ After $(n=40)$} & \multirow[t]{2}{*}{ P-value } \\
\hline & No. & $\%$ & No. & $\%$ & \\
\hline Before and during insertion of IAB & 14 & 35.0 & 31 & 77.5 & $0.000 * *$ \\
\hline Immediately after insertion of IAB & 10 & 25.0 & 32 & 80.0 & $0.000 * *$ \\
\hline Care of the central lumen & 11 & 27.5 & 31 & 77.5 & $0.000 * *$ \\
\hline Assessment guidelines after insertion & 15 & 37.5 & 27 & 67.5 & $0.007 * *$ \\
\hline Weaning and IABP removal & 11 & 27.5 & 22 & 55.0 & $0.012 *$ \\
\hline
\end{tabular}

Figure (1): The total score of nurses' knowledge and practice before and after teaching program. It was observed that there were statistical significant differences between nurses' knowledge categories indicating good knowledge after teaching program, compared with poor knowledge before teaching program.

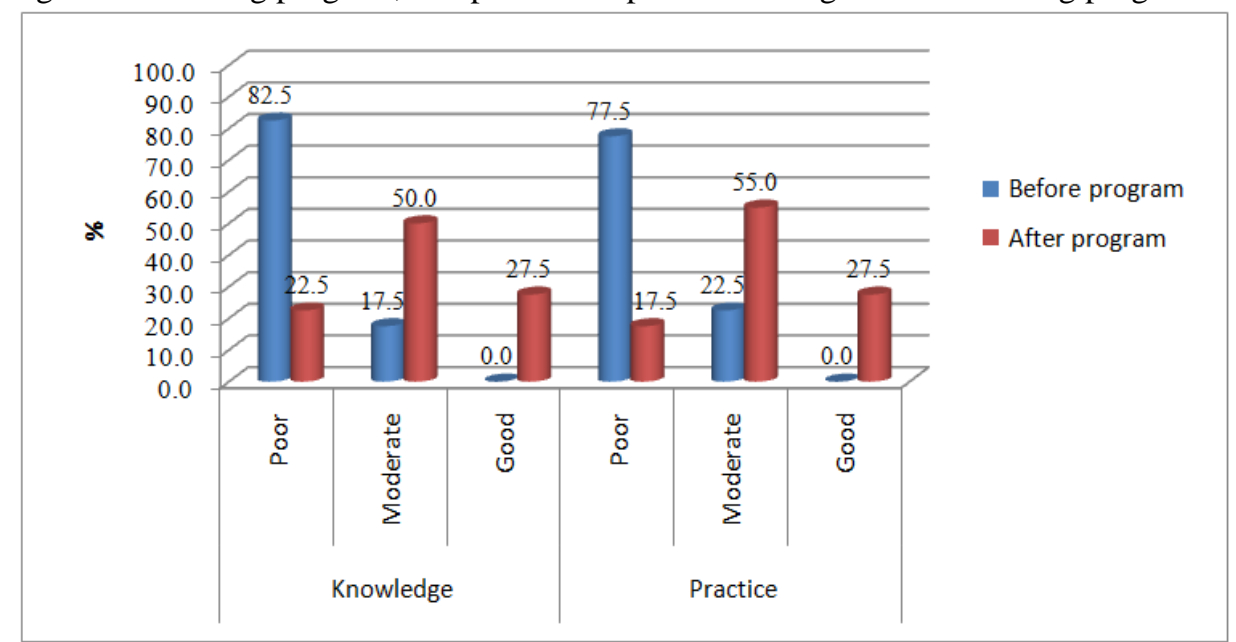

Figure (1): The total score of nurses' knowledge and practice before and after teaching program

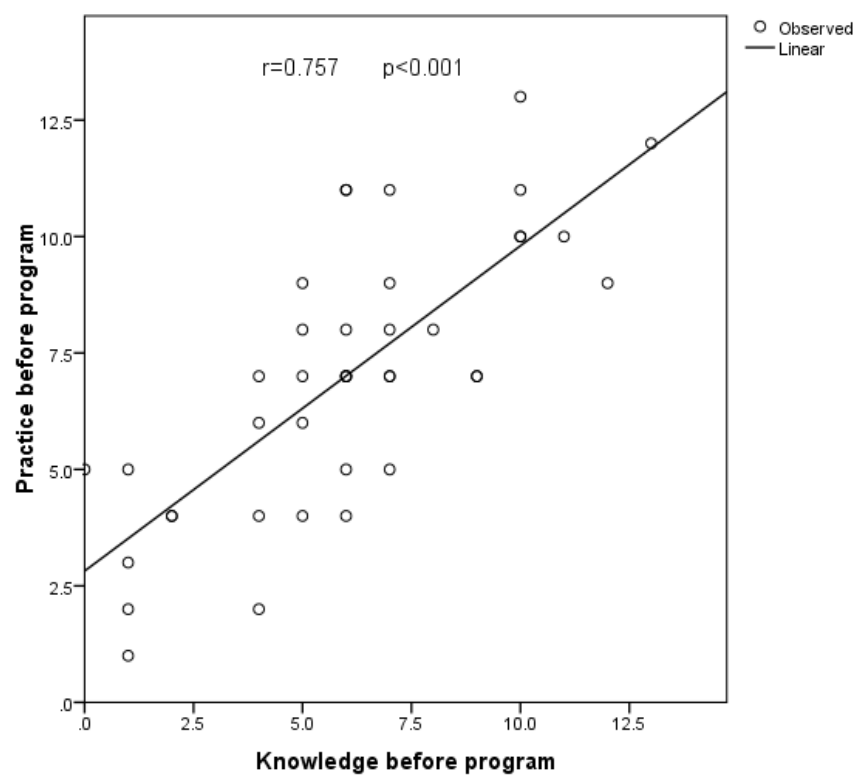

Figure (2): Correlation between total score of nurses' knowledge with practice before teaching program 


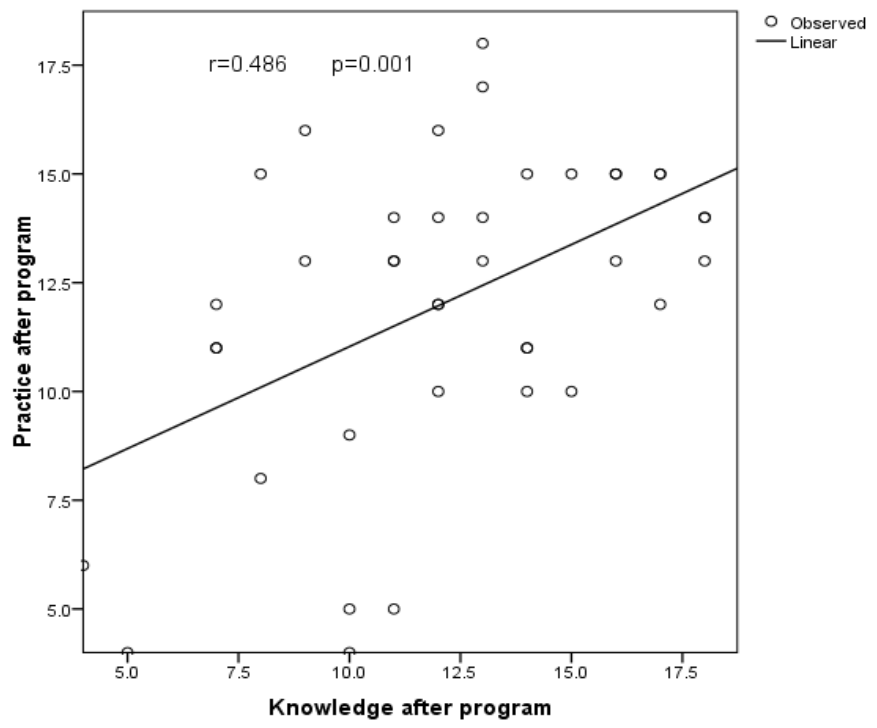

Figure 3: Correlation between total score of nurses' knowledge with practice after teaching program

\section{Discussion}

Intra-aortic balloon pump (IABP) is the most widely used temporary mechanical circulatory assist device for supporting failing circulation. The present study stated that all of the studied sample was females. This finding is in agreement with that of Rushdy, Mohammed, and Elfeky (2010) who conducted a study about implications for advancement of Egyptian nursing, and found that nursing in Egypt is primarily a female occupation and very few men are admitted to nursing programs in the university sector. As well, Abdullah, E., Mohammed, W., \& Ismail(2014) conducted a study about relationship between perceived organizational climate and conflict management strategies among nurses in Cairo University Hospitals and revealed that the majority of nurses were female.

As regards to age group, more than two thirds of the studied sample was young adults. This finding is in agreement with that of El Feky, \& Ali, (2013) who studied "nurses' practices and perception of delirium in the intensive care units in Egypt" and revealed that around three quarters of the studied sample was approximately in same age groups of the current study subjects. A young adult is generally a person in the age range of 20 to 40 year. Young adulthood can be considered as a period of stabilization yin which the individual makes career decision and becomes more adaptable and responsive to challenges. Concerning qualifications, the current study revealed that more than half of the studied sample had bachelor nursing degree. Finding of the present study is in agreement with that of Abd el- kader, \& Ali, (2012) who studied critical care nurses' knowledge and practice of fever management at a university hospital and revealed that more than two thirds of the studied sample had bachelor degree. However, this finding is contradicted by El Feky, \& Ali, (2013) and Abudahi, Fekry, \&Abdelwahab, (2012) who revealed that the great majority of their studied samples were diploma nurses. These differences "from the researcher's point of view" may be related to different types of nursing recruitment and variation of patient acuity level in the selected ICUs.

Provision of teaching may equip critical care nurses who care patient with IABP with the knowledge and skills to ameliorate the previously highlighted problems. Aiming to provide sufficient information to enable nurses to cope with all aspects and implications of the diseases and assume ultimate responsibility for their health care. Education or teaching can equip nurses with the skills to recognize and alleviate fear and anxiety, to identify and deal with stress-provoking situations and to express the emotional meaning the illness has for them. (Mahgoub etal,2014) Nurses' knowledge level about care of patients connected to IABP: In the current study, the finding data that answered the first research hypotheses, it states " There will be significant difference between posttest knowledge scores to the pretest knowledge scores following implementation of teaching program and revealed that the nurses' knowledge scores about anatomy and physiology of the heart significant improved after teaching program. On the same line with this findings was that of Huang \& Hsu (2012) who constructed a clinical teaching program about "standardized operating procedure for intra-aortic balloon pump support" and revealed that many nurses were hesitant to use IABPs due to lack of knowledge regarding their use. The reasons for lack of knowledge pertinent to IABP "from the researcher's point of view" may be related to lack of: continuing educational programs or sessions about this therapeutic intervention, supervision, continuous evaluation of nurses' practice, and cooperation between multidisciplinary health care team members (nurses - physicians). This view supported by (Abdel naeem,2015)

Finding of current study that the nurses' knowledge scores about principles of IABP significant increased post teaching program. To optimize the physiologic benefit of IABP, minimize IABP risks, and allow 
cardiac support to be individualized in response to variations in heart function, patient observation must be a continual process. Thorough knowledge, continual assessment and prompt intervention are essential in determining the best patient response. Thomas, 2013advises hemodynamic assessment includes: heart rate; arterial blood pressure; central venous pressure; pulmonary artery pressure; pulmonary capillary wedge pressure; and cardiac output. Nurses are required to adhere to accepted standards of practice and professional performance. (winters\&Echeverri 20012) Nurses' practices level regarding care of patients connected to IABP: The current study findings that answered the second research hypotheses There will be significant difference between posttest practice scores to the pretest practice scores following implementation of teaching program and revealed that the majority of the studied sample had poor practice levels regarding assessment of nurses' practice was done during preparation for insertion, caring of patient connected to IABP and during weaning and removal of IABP with highly statistical significant differences before and after teaching program .

As well, the current study findings are in agreement with that of Lewis, Ward \& Courtney (2009), who conducted a study about IABP in heart failure management and concluded that; to achieve the best possible outcome for a patient managed with IABP, nursing and medical staff require specialized skills. Nurses must continually assess changes in patients' condition which require knowledge of the cardiovascular system, therapeutic effects of IABP and potential adverse events. Consequently, Jing et al (2010) conducted a study to investigate postoperative nursing of percutaneous coronary intervention therapy combined with IABP in patients with cardiogenic shock and revealed that, the main points of nursing care related to those patients were strengthening observation, choosing the appropriate posture of patients, choosing appropriate cessation time of the counterpulsation pump and preventing complication actively. The reasons of low practice level in the current study may be relevant "from the researcher's point of view" to lack of scientific references, and nurses aren't used self-learning. In addition, nurses' practices were based on traditions and imitations. This point of view is supported by Bateson \& Kennedy (2011), who studied nurses' experiences in caring for conscious patients receiving IABP therapy for treatment of heart failure, and revealed that the initial fear of participants was when they called for first caring of patients receiving IABP therapy and this was overcome through education and supported experience. Although participants recognized the general importance of technical' competence, general nursing care was prioritized by participants more than specific care related to IABP. This in addition to participants' feeling that IABP therapy was a means to an end and representing hope for survival.

As regarding the relationship between knowledge and practice The finding of this study supported the hypothesis III which stated that positive relation will exist between knowledge and practice score obtained by critical care nurses receiving teaching program. This reflects the importance of integration between theory and practice .In the same line ,These result are in line with the result reported by Elazazay H., et al (2012) and Alshonee et al. (2014) who found that a positive significant correlation between nurses knowledge and performance related to CPR pre and one month post the training program. Aly A (2010) reported that there was significant correlation between total basic life support knowledge and practice scores. Critical care nurses managing IABP must be able to participate in the continual assessment, interpretation of the pressure waves and routinely documented as evidence of IABP effectiveness. Therefore, the current study aimed to evaluate the effect of implementing intra-aortic balloon pump teaching program on critical care nurse's knowledge and practice

\section{Conclusion}

Based on findings of the current study, it can be concluded that, critical care nurses have vital role in assessment and management of critically ill patients connected with IABP.To achieve the best patient outcome and lower mortality rates, the nursing staff requires specialized skills and updating knowledge through carrying out continuing educational programs about IABP.

\section{Recommendation}

- Developing and regularly assessing nursing competencies through stimulation techniques.

- Periodic training sessions for nurses in intensive care units to improve practices about assessment and management of patients connected to IABP.

- Construction of workshop for critical care nurses about therapeutic modalities.

- The study should be replicates on a larger probability sample from different geographical locations in Egypt

\section{Acknowledgment}

I would like to acknowledge the contribution of all the participants who kindly agreed to take part in the study. They generously gave their time and attention to conduct this study. This study would have been impossible without their generosity. 


\section{References}

[1]. Abdel naeem M. (2015) .Effect of implementing CPR teaching program on knowledge and skills of critical care nurses at Assiut university hospital.Doctoral thesis,

[2]. Abdkader, L. M., \& Ali, N. S. (2012). Critical Care Nurses' Knowledge and Practice of Fever Management at a University Hospital. Journal of American Science, 8(12), 1545-1553.

[3]. Abdullah, E., Mohammed, W., \& Ismail, (2014). Nurses' Knowledge and Practices about Administration of Medications via Nasogastric Tube among Critically Ill Patients. Journal of Education and Practice, 5(1), 147

[4]. Alshonee S, Elsayed E, Elsharkawy H and Mohamed A. (2014) Effect of educational training about cardiopulmonary resuscitation on pediatric nurses' practice International Journal of Current Research Vol. 6, Issue, 09, p.8781-8788,

[5]. Aly A, (2010) Impact of a Basic life Support Training Program on nurses' Knowledge and Performance at Emergency Room. Doctorate thesis. Faculty of Nursing. Port Saied University.

[6]. Bateson, M., \& Kennedy, S. (2011).Poster Exploring Nurses' Experiences of Caring for Conscious Patients Receiving Intra-Aortic Balloon Pump Therapy for Heart Failure. European Journal of Cardiovascular Nursing, 10(1 suppl), S27- S27.

[7]. Elazazay H, Abdelazez A and Elsaie O. (2012) Effect of Cardiopulmonary Resuscitation Training Program on Nurses Knowledge and Practice Life Science Journal;9(4)

[8]. Ezzat M.(2005) Nursing care guidelines for patients with open heart surgery,1st ed,Syrian join for cardiac medicine and surgery.P $103-110$

[9]. Hanlon-Pena P and Quaal S.(2011 ).Intra-aortic balloon pump timing: Review of evidences supporting current practice. AJCC, Volume 20, No.

[10]. http://ca.maquet.com/clinician information/educational-materials

[11]. Huang, Y \& Hsu, L. (2012). [Clinical teaching program: standardized operating procedure for intra-aortic balloon pump support]. Hu li zazhiThe journal of nursing, 59(4), 88-93.

[12]. Jing, H., Hong-mei, Y., Chun-xue, L., You-hong, X., \& Xia, Y. (2010). Postoperative Nursing of Percutaneous Coronary Intervention Therapy Combined with Intra-aortic Balloon Pump in Patients with Cardiogenic Shock Caused by Acute Myocardial Infarction [J]. Nursing Journal of Chinese People's Liberation Army, 3.

[13]. Mahgoub A, Mohamed W, Mohamed M and Kishk Y. (2013) .mpact of Knowledge about Early Ambulation on Patients' Satisfaction Post Percutaneous Coronary Intervention, at Assiut University Hospital, medical journal of cairo university;2(4), 5-13.

[14]. Morton, P. G., \& Fontaine, D. K (2012). Essentials of Critical Care Nursing: A Holistic Approach:10ed. Wolters Kluwer Health/Lippincott Williams \& Wilkins, 173.

[15]. Parissis, H., Leotsinidis, M., Akbar, M. T., Apostolakis, E., \&Dougenis, D. (2010). The need for intra aortic balloon pump support following open heart surgery: risk analysis and outcome. J Cardiothoracic Surgery, 5(5), 20. 19.

[16]. Qaddumi, J., \&Khawaldeh, A. (2014). Pressure ulcer prevention knowledge among Jordanian nurses: a cross-sectional study. BMC nursing, 13(1), 6. 20 .

[17]. RushdyT, Mohammed W, and Elfeky H.(2010) Nurses' knowledge and practice regarding care of patients connected to intraaortic balloon pump at Cairo university hospitals,Egyptian nursing journal ,p13-17

[18]. Thomas, M. P. (2013). A study to evaluate the effectiveness of video assisted teaching program on knowledge and practice regarding cardioversion and defibrillation among staff nurses working in cardiac unit.Journal of CardiovascularMedicine, 8(5)20-33

[19]. TscheschlogB,Jauch A. (2015 ).Emergency nursing. made incredibly easy 2 thed . wolters Kluwer health P.233-235

[20]. UrdenL,StancyK,Lough M.(2010 ) Critical care nursing ,diagnosis and management, by mosby , an imprint of Elsevier Inc .P534536.

[21]. Ward L, Courtney D and Mary D. (2009) The intra-aortic balloon pump in heart failure management: Implications for nursing practice. Australian Critical Care, 22(3). pp. 125-131.

[22]. Winters C and Echeverri R. (2012)Teaching strategies to support evidence based practice , CriticalCareNurse 3(32),P.233-23

[23]. Woodruff D. (2016)Critical care nursing.made incredibly easy 4 thed . wolters Kluwer health P.233-235 